\title{
Rehabilitation of Fine Motor Coordination of Individuals with Chronic Alcohol Dependence
}

\author{
Neelu Sharma ${ }^{1}$, Om Prakash $^{2}$, Sarika Alreja ${ }^{3}$, K. S. Sengar ${ }^{4}$, Amool R. Singh ${ }^{5}$
}

\section{ABSTRACT}

Long term alcohol abuse causes physical, cognitive, psychological and neuropsychological deficit in alcoholic individual. Current study intends assess and rehabilitate fine motor coordination of chronic alcohol dependent cases. Seven chronic cases of alcohol dependence were selected from de-addiction ward of Ranchi Institute of Neuropsychiatry and Allied Sciences, Kanke. All the cases were assessed on LNNB \& AIIMS Motor function scale. Each patient was individually given one month rehabilitation training with Talking Pen. All the cases were assessed in pre and post test condition. Result was analyzed using Wilcoxin Sign Rank Test. Result reveals there was significant difference between patient's pre and post intervention performance which suggests improved fine motor functioning of the alcohol dependent individuals.

Keywords: Rehabilitation, Chronic Alcohol Dependence, Fine Motor Coordination

It is well known truth that alcohol abuse produces deficit in different functional areas of alcoholics. These deficits comprise dysfunction in attention, memory, thinking, problem solving including fine motor coordination and various cognitive, behavioral and social problems in due course of time. Persistent alcohol abuse results in a variety of neuropsychological abnormality such as regional brain structural damage (Sullivan 2000), and characteristic behavior motor deficit (Oscar et al, 2000). Significant impairment has been found on motor speed functions (Parks et al, 2003), muscle strength, and visual motor integration such as hand eye coordination (Tarter \& Jones, 1971). Though neuropsychological functioning of alcoholic individuals have been studied widely, only a few studies have reported efficacy of rehabilitation program in motor dysfunction.

There is sufficient literature suggesting occurrence of motor dysfunction in alcoholic patients. The detoxified alcoholics tapped significantly slower than normal controls with each hand and

${ }^{1}$ Ph. D Scholar (Clinical Psychology) RINPAS, Kanke, Ranchi, India.

${ }^{2}$ Clinical Psychologist, GMCH, Department of Psychiatry, Chandigarh, India.

${ }^{3}$ Ph.D in Clinical Psychology.

${ }^{4}$ Additional Professor, Department of Clinical Psychology, RINPAS, Kanke, Ranchi, India.

${ }^{5}$ Professor\& Head, Department of Clinical Psychology, RINPAS, Kanke, Ranchi, India.

*Responding Author

(C) 2015 I N Sharma, O Prakash, S Alreja, K Sengar, A Singh; licensee IJIP. This is an Open Access Research distributed under the terms of the Creative Commons Attribution License (http://creativecommons.org/licenses/by/2.0), which permits unrestricted use, distribution, and reproduction in any Medium, provided the original work is properly cited. 
chronic alcoholic patients had impaired cognitive functions (Fals et al, 1994; Bates et al, 2002; Parks et al, 2003). However, till date very few studies have tried to remediate the fine motor functioning of alcoholic patients.

Alcohol consumption negatively effects physical and neuropsychological functioning of individuals who consume alcohol from a long period of time. It has been found in studies that chronic alcoholics confront impairment in specifically sustained and divided attention tasks, immediate effects on multiple cognitive-motor processing domains and decision-making, information processing, and judgment (Hindmarch et al, 1991; Moskowitz \& Sharma 1974).

Here a question arises that whether these deficits are direct consequence of alcohol abuse. This question is difficult to answer and determine the effect of alcohol abuse on motor functioning of alcohol dependents. However, in present study we made some effort to deal with some of these issues. In current study the aims were to assess fine motor dysfunction and decipher the improvement in fine motor functioning of chronic alcohol dependence cases through fine motor rehabilitation techniques.

Alcoholics who either abstain from alcohol newly or from long time demonstrate deficit in learning and memory, abstraction and problem solving, and perceptual-motor skills (Oscar et al, 2000; Sullivan et al, 2000). Bilateral tremble and ataxia of the extremity are examples of motor dysfunction usually seen in alcoholic individuals when they discontinue drinking behavior (Welch et a., 1997; Sullivan et al, 2000, 2002). A number of researchers studied to know more about motor dysfunction in alcoholics, mainly because cerebellum is sensitive in alcohol related brain damage (Baker et al, 1999; Parks et al, 2002).

Previous researches demonstrate that some alcohol-dependent patients show disturbances of gait and posture (Sullivan et al, 2002). During abstinence or withdrawal period deficits in gait and posture persist (Sullivan et al, 2002). There is disagreement among researchers on the execution of small synchronized motor movement in upper limb. Some researchers states that abstinent alcoholics perform poor on the complex motor tasks than non alcoholic individuals (Fama et al, 2007; Parks et al, 2003; Sullivan et al, 2002). However, other researchers says that sober alcoholics and healthy controls perform equally well on these complex motor tasks (Sullivan et al, 2000).

The present study has tried to focusing the areas which has often overlooked and very less studied. It has been an attempt to understand nature and severity of fine motor deficit in chronic alcoholic patients and rehabilitate these deficits with the remediation training. 


\section{METHODS AND MATERIALS}

Aims

- To assess the level of deficit in Fine Motor Coordination of Individuals with Chronic Alcohol Dependence

- To remediate Fine Motor Coordination of Individuals with Chronic Alcohol Dependence

\section{Design}

This study was a center based confirmatory study using individual case study: pre and post test design.

\section{Venue}

Drug De-addiction unit of Ranchi Institute of Neuropsychiatry and Allied Sciences, Kanke, Ranchi, Jharkhand, India

\section{Sample}

Seven male patients of the age group 30-45years, right handed ,educated up to matriculation, employed/ unemployed belonging to middle/lower socioeconomic status of rural and urban background of Jharkhand and Bihar, having a history of approximately 10 years of alcohol intake, presently admitted in drug de-addiction ward of RINPAS were taken using purposive sampling. All the participants fulfilled the ICD-10 criteria for alcohol dependence. Any other comorbid psychiatric/neurological/major physical illness was ruled out. Patients were given the informed consent for the study.

\section{Inclusion Criteria}

- Male patients

- Age range 30-45 years

- Right handed.

- History of alcohol intake for at least 10 years with dependence pattern for at least 3 years

- Abstinent period of minimum three weeks following detoxification phase

- At least 10 years of Schooling

- Patient who gave consent for the study

\section{Exclusion Criterion}

Patients with any co-morbid conditions

Family history of mental illness

Uncooperative patients 


\section{Tools for the Assessment}

- SOCIO DEMOGRAPHIC \& CLINICAL DATA SHEET

This is semi structural Performa especially drafted for this study. It contains information about the socio demographic variables like-age, sex, education, marital status, religion, occupation, socio-economic status \& domicile of the subject. It also includes the clinical details likediagnosis, age of onset, total duration of illness, and history of alcohol or substance abuse, family history of mental illness, any history of significant head injury, seizure, mental retardation and any other significant physical or psychiatric illness.

- SEVERITY OF ALCOHOL DEPENDENCE QUESTIONNAIRE FORM- C (SADQ-C) (STOCK WELL ET AL, 1994)

The Severity of Alcohol Dependence Questionnaire is a 20-item questionnaire designed to measure the severity of alcohol dependence.

The Severity of Alcohol Dependence Questionnaire was developed by the Addiction Research Unit at the Maudsley Hospital. The AUDIT questionnaire, by contrast, is used to assess whether or not there is a problem with dependence.

The severity rating for the each 20 item is based on the subjective report of the patient about his/her condition. Answers to each question are rated on a four-point scale: Almost never - 0 , sometimes 1, often 2, nearly always and 3. A score of 31 or higher indicates "Severe Alcohol Dependence". A score of 16 -30 indicates "Moderate Dependence" and a score of below 16 usually indicates only a mild physical dependency.

- HAND PREFERENCE BATTERY

This scale is constructed by Annett (1970) and published in British Journal of Psychology, volume 61. It has six items. Based on this scale dominant hemisphere is ascertained.

- AIIMS COMPREHENSIVE NEUROPSYCHOLOGICAL BATTERY ADULT FORM MOTOR FUNCTION SCALE (GUPTA ET AL, 2000)

The AIIMS Comprehensive Neuropsychological Battery is potentially useful for both diagnosis and rehabilitation. It is a standardized neuropsychological battery for a wide variety of patients with varying deficits. The battery has a further benefit of requiring a relatively short administration time. The 160 items in Hindi of the test are spread over 10 primary scales which are as follow: Motor scale, Tactile scale, Visual scale, Receptive speech, Expressive speech, Reading scale, Writing scale, Arithmetic scale, Memory scale, and Intellectual process scale. It is a 5 point rating scale from $0-4$ where 0 shows no brain damage, scores 1 , 2, and 3 suggest intermediate performance and score 4 indicating brain damaged performance.

- LURIA NEBRASKA NEUROPSYCHOLOGICAL BATTERY GOLDEN ET AL 1985(FORM-I, MOTOR FUNCTION SCALE)

Luria Nebraska Neuropsychological Battery Form-I (Golden et al., 1985) has eleven sub scales Motor scale, Rhythm scale, Tactile scale, Visual function scale, Receptive speech, Expressive speech, Reading scale, Writing scale, Arithmetic scale, Memory scale, and Intellectual process scale. Motor function scale is longest scale on the battery consists 51 items and one of the most useful scale. As the first scale, it includes initial items which is very easy and which most clients are capable of doing. 
- $\quad$ THE TALKING PEN (WAYNE ENGINEERING, 1974)

Since 1974 the Talking Pen has been the premier instrument for developing fine-motor skills through pattern tracing. The Talking Pen is a proven tool for developing perceptual-motor skills from basic diagnostics to advanced training. Although applications are almost unlimited, it is most often used to diagnose and develop gross and fine motor skills, hand-eye coordination, laterality, directionality, auditory perception, form perception, ocular pursuits and spatial relationships. It has been used successfully with the learning disabled, the visually impaired, the brain injured, the hyperactive and the dysgraphic individual.

\section{Tool for Intervention}

\section{- THE TALKING PEN}

The pen is triangular shaped and easy to hold and operate. Individual can grasp writing the pen like any writing tool with the thumb, index finger and middle finger Individual should hold the pen at no less than a 45 angle from the writing space.

An infra-red light and fiber optic sensor in the tip of the pen sense reflect as the user traces a pattern with the pen and provide immediate auditory feedback if the user wanders off the pattern. The pen is quiet when the tip is on a black image and emits a buzz when the tip is on a white surface.

The aim of the intervention was to rehabilitate the fine motor coordination of the alcohol dependence cases which was deteriorated due to chronic alcohol dependence. Therefore 6 exercises out of eight exercises of Talking Pen were applied with the each patient individually.

\section{Procedure}

All the participants were selected according to inclusion \& exclusion criteria. Sociodemographic and clinical information was collected by using the Socio demographic \& Clinical Data Sheet. Hand Preference Battery was administered to ascertain the handedness of the patients. SADQ-C was done to assess the severity of alcohol dependence of the patients (only cases who had scored more than 31 or above on SADQ-C were selected for the study). All the patients were trained individually with the help of the Talking Pen everyday for 30 minutes for a period of one month and pre and post training performance was assessed. The motor function scales of the All India Institute of Medical Science Comprehensive Neuropsychological Battery. (AIIMSCNB)\& Motor functions scale of the Luria Nebraska Neuropsychological Battery (LNNB: Form-I) was also administered to each participant individually pre and post intervention condition to assess the status of motor functions.

\section{Statistical Analysis}

Data was entered, coded and statistically Analyzed by applying Wilcoxin Sign Rank test to find difference in pre intervention and post intervention condition. Percentage was also used to show the sociodemographic details of the patients. 


\section{RESULT}

Table: 1 reveals Sociodemographic characteristics of alcohol dependent individuals. Only male patients were included in the study. Most of patients were between the ages of 30 to 40 years. Majority of the cases were educated up to matriculation (57\%), majority of the cases (58\%) were Christian followed by Hindu (42\%) , majority of cases were belonging to urban area (71\%) followed by rural (29\%), majority of cases were employed (71\%), married (57\%) and showing history of chronic alcohol dependence (since 10 years).

Table: 2 show performance of patients on Motor Function Scale of LNNB \& AIIMS Comprehensive Battery.

On LNNB in pre intervention assessment Mean \pm SD $=24.00 \pm 7.81$ and post intervention assessment it was $11.71 \pm 2.49, \mathrm{Z}$ score $=2.37$. Difference between pre and post intervention assessment was significant on .01, suggests significant difference in pre and post test performance of the cases.

On AIIMS Battery in pre intervention assessment Mean \pm SD $=56.71 \pm 8.59$ and post intervention assessment it was $41.28 \pm 2.92, \mathrm{Z}$ score $=2.37$. Difference between pre and post intervention assessment was significant on .01

Table: 3 shows baseline assessment and post intervention assessment of performance of all the seven cases individually on Talking Pen. Six exercises i.e. Eye Hand Coordination, Cognitive Motor Skill, Cross Line Directionality, Basic Graphic Motor Skill, Cursive Writing Skill and Manuscript Skill were assessed and rehabilitate with the help of Talking Pen. Assessment was done in terms of number of errors done on each exercise and time (in seconds) taken in completion of exercise. All the seven cases were assessed individually on each exercise in pre and post intervention settings. This table also demonstrates that all the seven patients took more time and did more errors in pre test condition on all the exercises. After one month intervention (each patient individually) there were marked decreased in time and errors done by the patients on all exercises of Talking Pen. Thus the table reveals that significant improvement occurred in performance of the Subjects which indicates towards improved fine motor coordination.

Table. 1 Showing Sociodemographic Characteristics of all the seven Alcohol Dependent Cases

\begin{tabular}{|l|l|l|}
\hline \multirow{2}{*}{ Age } & $30-40$ yrs & $68 . \%$ \\
\cline { 2 - 3 } & $41-\quad 45 \mathrm{yrs}$ & $32 \%$ \\
\hline \multirow{2}{*}{ Suration } & 10 yrs & $70 \%$ \\
\cline { 2 - 3 } & $11-15$ yrs & $30 \%$ \\
\hline \multirow{2}{*}{ Education. } & Male & $100 \%$ \\
\hline \multirow{2}{*}{ Occupation. } & Metric & $57 \%$ \\
\cline { 2 - 3 } & Intermediate & $43 \%$ \\
\hline \multirow{2}{*}{ Marital status } & Unemployed & $29 \%$ \\
\cline { 2 - 3 } & Employed & $71 \%$ \\
\hline \multirow{2}{*}{ Religion. } & Unmarried & $43 \%$ \\
\cline { 2 - 3 } & Married & $57 \%$ \\
\hline \multirow{2}{*}{ Domicile } & Hindu & $42 \%$ \\
\cline { 2 - 3 } & Christian & $58 \%$ \\
\hline \multirow{2}{*}{ S.E.S } & Rural & $29 \%$ \\
\cline { 2 - 3 } & Urban & $71 \%$ \\
\hline & Lower SES & $58 \%$ \\
\cline { 2 - 3 } & Middle & $42 \%$ \\
\hline
\end{tabular}


Rehabilitation of Fine Motor Coordination of Individuals with Chronic Alcohol Dependence

Table 2 showing patients pre \& post intervention performance on LNNB \& AIIMSCNB of all seven cases

\begin{tabular}{|c|c|c|c|c|c|}
\hline \multirow[t]{2}{*}{ Assessment } & \multirow{2}{*}{$\begin{array}{l}\text { Pre intervention } \\
\text { assessment } \\
\text { Mean } \pm \text { SD }\end{array}$} & \multirow{2}{*}{$\begin{array}{l}\text { Post intervention } \\
\text { assessment } \\
\text { Mean } \pm \text { SD }\end{array}$} & \multicolumn{3}{|c|}{$\begin{array}{l}\text { Wilcoxin sign rank } \\
\text { test }\end{array}$} \\
\hline & & & Sign & $\begin{array}{l}\text { Mean } \\
\text { Rank }\end{array}$ & $\begin{array}{l}\mathrm{Z} \\
\text { score }\end{array}$ \\
\hline \multirow[t]{2}{*}{ LNNB } & \multirow[t]{2}{*}{$24 \pm 7.81$} & \multirow[t]{2}{*}{$11.71 \pm 2.49$} & + & .00 & \multirow[t]{2}{*}{$2.37 * *$} \\
\hline & & & - & 7.00 & \\
\hline \multirow[t]{2}{*}{ AIIMS } & \multirow[t]{2}{*}{$56.71 \pm 8.59$} & \multirow[t]{2}{*}{$41.28 \pm 2.92$} & + & .00 & \multirow[t]{2}{*}{$2.37 * *$} \\
\hline & & & - & 7.00 & \\
\hline
\end{tabular}

$* * \mathrm{p} \leq .01$ level of significance

Table 3 showing patient's pre and post intervention performance on Talking Pen regarding time \& errors

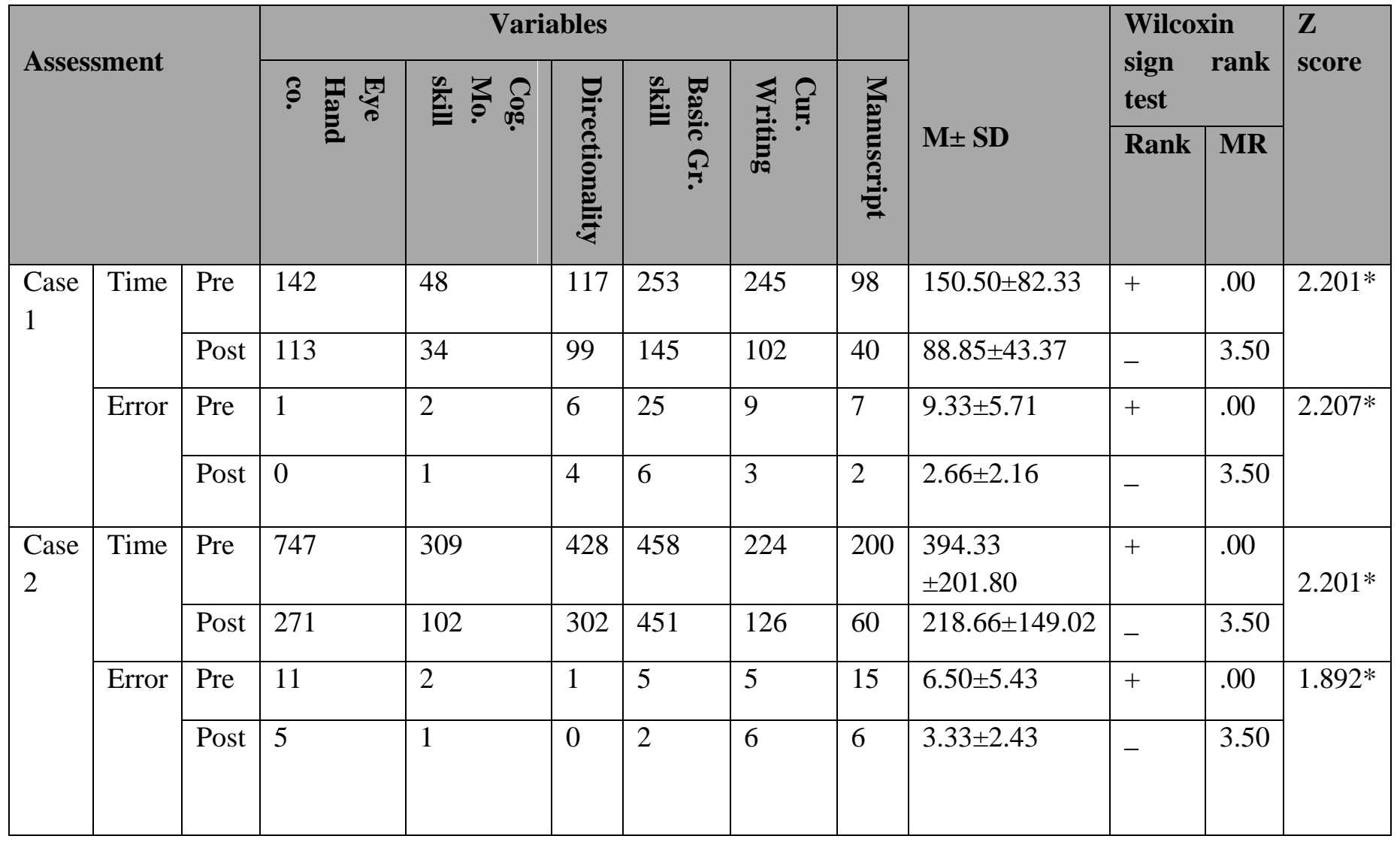


Rehabilitation of Fine Motor Coordination of Individuals with Chronic Alcohol Dependence

\begin{tabular}{|c|c|c|c|c|c|c|c|c|c|c|c|c|}
\hline \multirow{4}{*}{$\begin{array}{l}\text { Case } \\
3\end{array}$} & \multirow[t]{2}{*}{ Time } & Pre & 291 & 95 & 153 & 436 & 357 & 75 & $222.50 \pm 145.96$ & + & .00 & \multirow[t]{2}{*}{$2.201 *$} \\
\hline & & Post & 90 & 49 & 79 & 212 & 188 & 40 & $109.67 \pm 72.75$ & - & 3.50 & \\
\hline & \multirow[t]{2}{*}{ Error } & Pre & 6 & 5 & 9 & 11 & 19 & 8 & $9.66 \pm 5.04$ & + & .00 & \multirow[t]{2}{*}{$2.201 *$} \\
\hline & & Post & 3 & 2 & 2 & 4 & 6 & 2 & $3.16 \pm 1.46$ & - & 3.90 & \\
\hline \multirow{4}{*}{$\begin{array}{l}\text { Case } \\
4\end{array}$} & \multirow[t]{2}{*}{ Time } & Pre & 304 & 65 & 135 & 360 & 305 & 70 & $206.65 \pm 131.55$ & + & .00 & \multirow[t]{2}{*}{$2.201 *$} \\
\hline & & Post & 203 & 35 & 88 & 150 & 140 & 30 & $107.67 \pm 68.73$ & - & 3.50 & \\
\hline & \multirow[t]{2}{*}{ Error } & Pre & 9 & 0 & 4 & 12 & 13 & 10 & $8.00 \pm 5.01$ & + & .00 & \multirow[t]{2}{*}{$2.023 *$} \\
\hline & & Post & 2 & 0 & 1 & 3 & 4 & 4 & $2.33 \pm 1.52$ & - & 3.00 & \\
\hline \multirow{2}{*}{$\begin{array}{l}\text { Case } \\
5\end{array}$} & \multirow{2}{*}{ Time } & & 214 & 68 & 169 & 268 & 191 & 110 & $170.00 \pm 72.09$ & + & .00 & \multirow{2}{*}{$2.207^{*}$} \\
\hline & & Post & 151 & 52 & 154 & 192 & 128 & 128 & $129.50 \pm 48.67$ & - & 3.50 & \\
\hline
\end{tabular}

\begin{tabular}{|c|c|c|c|c|c|c|c|c|c|c|c|c|}
\hline & Error & Pre & 12 & 0 & 10 & 8 & 7 & 12 & $8.16 \pm 4.49$ & + & .00 & $2.041^{*}$ \\
\hline & & Post & 4 & 0 & 4 & 2 & 0 & 4 & $2.33 \pm 1.96$ & - & 3.00 & \\
\hline \multirow{4}{*}{$\begin{array}{l}\text { Case } \\
6\end{array}$} & \multirow[t]{2}{*}{ Time } & Pre & 202 & 71 & 98 & 205 & 167 & 123 & $144.33 \pm 55.67$ & + & .00 & \multirow[t]{2}{*}{$2.201^{*}$} \\
\hline & & Post & 170 & 48 & 35 & 150 & 90 & 75 & $94.66 \pm 54.55$ & - & 3.50 & \\
\hline & \multirow[t]{2}{*}{ Error } & Pre & 8 & 7 & 6 & 13 & 10 & 6 & $8.33 \pm 2.73$ & + & .00 & \multirow{2}{*}{$2.207^{*}$} \\
\hline & & Post & 2 & 3 & 0 & 6 & 2 & 3 & $2.66 \pm 1.96$ & - & 3.50 & \\
\hline \multirow[t]{4}{*}{$\begin{array}{l}\text { Case } \\
7\end{array}$} & \multirow[t]{2}{*}{ Time } & Pre & 304 & 85 & 130 & 369 & 309 & 80 & $\begin{array}{l}212.83 \pm 128.6 \\
8\end{array}$ & + & .00 & \multirow[t]{2}{*}{$2.207^{*}$} \\
\hline & & Post & 203 & 35 & 88 & 150 & 140 & 30 & $107.67 \pm 68.73$ & - & 3.50 & \\
\hline & \multirow[t]{2}{*}{ Error } & Pre & 9 & 0 & 4 & 12 & 13 & 10 & $8.00 \pm 1.16$ & + & .00 & \multirow[t]{2}{*}{$2.203^{*}$} \\
\hline & & Post & 2 & 0 & 1 & 0 & 0 & 4 & $3.00 \pm 2.16$ & - & 3.00 & \\
\hline
\end{tabular}

$* \mathrm{p} \leq .05$ level of significance 
Table-4 Showing Qualitative Analysis of Neuropsychological Performance at Baseline and after Intervention of all the seven patients on LNNB

\begin{tabular}{|c|c|c|}
\hline \multirow{2}{*}{$\begin{array}{l}\text { Functions } \\
\text { C1 (Motor Functions) }\end{array}$} & \multicolumn{2}{|c|}{$\begin{array}{l}\text { No. of patients impaired on the Motor } \\
\text { Functions Scale }\end{array}$} \\
\hline & At Baseline & After Intervention \\
\hline Simple movement of hand & 0 & 0 \\
\hline Kinesthetic movement of hand & 4 & 2 \\
\hline Optic spatial organization & 6 & 1 \\
\hline • One plane & 3 & 0 \\
\hline - Double plane & 2 & 1 \\
\hline - Verbal command & 4 & 2 \\
\hline - Midline & 3 & 0 \\
\hline Smooth coordination of hand movement & 3 & 2 \\
\hline Complete forms of praxis & 4 & 1 \\
\hline Simple movement of oral area & 0 & 0 \\
\hline Smooth coordination of oral movement & 2 & 0 \\
\hline Oral praxis & 2 & 0 \\
\hline Selectivity of motor act & 4 & 2 \\
\hline$\bullet$ Form & 5 & 0 \\
\hline - Speed & 4 & 1 \\
\hline Verbal regulation of motor act & 3 & 0 \\
\hline
\end{tabular}

Table-4 shows qualitative analysis of patients' neuropsychological performance at baseline and after intervention. The qualitative analysis of the neuropsychological performance reveals that patient’s neuropsychological performance was markedly improved after intervention.

\section{DISCUSSION}

The present study was conceptualized to rehabilitate the fine motor coordination of chronic cases with alcohol dependence. The neuropsychological test was chosen to assess the motor dysfunction in alcoholic patients, because they are standardized, well known measures which can be scored reliably and have proven sensitive to frontal lobe dysfunction. The Talking Pen was chosen as intervention tool because it is a primary measure to improve fine motor coordination since its development.

Findings of the current study demonstrates that all seven patient's scores on Motor Functions Scale of LNNB \& AIIMS Comprehensive Battery(AIIMSCB Motor Function Scale), were more in pre test condition and it was markedly reduced after the intervention with the help of Talking Pen. The findings also suggest that there was significant improvement in patient's fine motor coordination after pattern tracing practice. Findings of the present study is consistent with 
previously done studies recommends pattern tracing is useful technique to remediate fine motor skill (Victor et al, 1989).

Our study is in agreement with the previous findings, reports that abstinence alcoholic shows impaired cognitive and motor functioning than the healthy controls (Biederman, 1991; Sullivan et al, 2002). Findings of some researchers conclude that abstinence alcoholic performs worse on the complex motor task than healthy controls (Fama et al, 2007). Result of our study reveals that the impaired motor functioning in chronic cases with alcohol dependence was significantly remediated through Talking Pen in one month remediation program. It is apparent from the table 3 that the eye hand coordination, cognitive motor skill, basic graphic motor skill, directionality, manuscript ability was significantly improved as there is significant reduction in time taken and errors done by the patients in completion of task (exercises of Talking Pen) after rehabilitation program.

Fine motor impairment of chronic alcohol dependent patient can be remediate with different behavioral, cognitive and neuropsychological rehabilitation programs and it was found to be proved in past literature as well as in the current study. Gorden et al., (1988) have shown neuropsychologically impaired alcoholics who had deficit in reasoning ability, visuospatial ability, visuomotor ability and learning and memory were improved after rehabilitation training program. Previous studies demonstrate that motor dysfunction in alcoholics with co morbid condition was more severe than alone alcohol dependence (Fama et al, 2007). Thus the present study has also tried to eliminate other co morbidities by ruling out any other co morbid psychiatry/ physical condition with alcohol dependence and focus specifically on rehabilitation of fine motor coordination.

However, findings of current study is somewhat inconsistent with the findings of some previously done researches which states that fine motor deficits of alcohol abstain individuals recovers by the time gap (Reed et al, 1992). This discrepancy may be due to methodological differences between current and past studies. Our study is a small sample study and it was only planned with the chronic alcohol dependent cases with severe alcohol dependence which needs medical as well as psychotherapeutic/instrument intervention.

Hence, the result of the present study is very encouraging for all those mental health professionals who are interested in the study of fine motor rehabilitation of alcoholic patients.

\section{CONCLUSION}

The result of the study suggest that chronic alcohol abuse has a destructive effect on fine motor functions and these dysfunction can be improve with the help of neuropsychological and fine motor remediation techniques which involves repetitive training and exercise. Hence, along with pharmacotherapy cognitive/fine motor remediation therapy would be helpful in the treatment of 
alcohol related motor problems. This study will have important implication in a daily function as well in professional function.

\section{LIMITATIONS}

Small sample size was a limitation of the present study. Since it was a pre and post test intervention study done individually with each patient who were in the state of abstinence, hence a control group was not included in study. Further a control group can be taken to make a comparison. The female population was excluded from the study thus limiting its generalization.

\section{Acknowledgement}

We are thankful to all alcohol dependent individuals who joined as participant in this work. Without their co-operation the work would have not been possible. We are also thankful to the nursing staff of RINPAS for their cooperation in conducting this research.

\section{REFERENCES}

Annett, M. (1970). A classification of hand preference by association analysis. British Journal of Psychiatry, 61, 303-321.

Bates, M.E., Bowden, S.C. \& Barry, D. (2002). Neurocognitive impairment associated with alcohol use disorder: implication for treatment. Experimental and Clinical Psychopharmacology, 10, 193-212.

Becker, J.T., Salthouse, T.A .(1999) Neuropsychological test performance in the acquired immunodeficiency syndrome: independent effects of diagnostic group or functioning. J Int Neuropsychol Soc 5:41-47.

Fals-Stewart, W., Schafer, J., Lucente, S., Rustine, T. \& Brown, L. (1994). Neurobehavioural consequences of prolonged alcohol and substance abuse: a review of findings and treatment implication. Clinical Psychology Review, 14, 775-788.

Fama, R., Eisen, J.C., Rosenbloom, M.J., Sassoon, S.A., Kemper, C.A., Deresinski, S., Pfefferbaum, A. \& Sullivan, E.V. (2007). Upper and Lower Limb Motor Impairments in Alcoholism, HIV Infection, and Their Comorbidity. Alcoholism: Clinical and Experimental Research, 31(6), 1038-1044

Golden, C. J., Purisch, A.D. \& Hammeke, T.A. (1985) Luria-Nebraska Neuropsychological Battery; Form-I and II (Manual). Los Angeles: Western Psychological Services.

Gordon, S.M., Kennedy, B.P. \& McPeake, J.D. (1988). Neuropsychologically impaired alcoholics: Assessment, treatment considerations, and rehabilitation. Journal of Substance Abuse Treatment, 5, 99-104.

Gupta, S., Khandelwal, S.K., Tandon, P.N., Maheshwari, M.C., Mehta, V.S., Mahapatra, A.K., Sundaram, K.R. \& Jain, S. (2000). The developmental standardization of a comprehensive Neuropsychological Battery in Hindi (Adult Form). Journal of personality and Clinical Studies. 16, 75-109.

Hindmarch, I., Kerr, J.S. \& Sherwood, N. (1991). The effects of alcohol and other drugs on psychomotor performance and cognitive function. Alcohol Alcohol, 26, 71-79. 
Moskowitz, H. \& Sharma, S. (1974). Effects of alcohol on peripheral vision as a function of attention. Hum Factors, 16, 174-180.

Oscar-Berman, M. Noronha, A., Eckardt, M.J., Warren, K. (2000). Neuropsychological vulnerabilities in chronic alcoholism. NIAAA's neuroscience and behavioral research portfolio. National Institute on Alcohol Abuse and Alcoholism Research Monograph 34. 149-58

Parks, M.H., Dawant, B.M., Riddle, W.R., Hartmann, S.L., Dietrich, M.S., Nickel, M.K., Price, R.R. \& Martin, P.R. (2002). Brain metabolic characterization of chronic alcoholics using 1H MRS. Alcohol Clinical and Experimental Research, 26, 1368-1380.

Parks, M.H., Morgan, V.L., Pickens, D.R., Price, R.R., Dietrich, M.S., Nickel, M.K. \& Martin,P.R.(2003). Brain fMRI Activation Associated with Self-Paced Finger Tapping in Chronic Alcohol-Dependent Patients. Alcoholism: Clinical and Experimental Research, $27,704-711$.

Reed, R.J., Grant, I. \& Rourke, S.B. (1992). Long-term abstinent alcoholics have normal memory. Alcoholism: Clinical and Experimental Research 16, 677-683.

Stockwell, T., Sitharthan, T., McGrath, D., \& Lang, E. (1994). The measurement of alcohol dependence and impaired control in community samples. Addiction, 89(2), 167-184.

Sullivan, E.V., Fama, Rosemary, Rosenbloom, Margaret J. \& Pfefferbaum, Adolf (2002). A profile of neuropsychological deficits in alcoholic. Women Neuropsychological, 16, 7483.

Sullivan, E.V., Rosenbloom, M.J., Lim, K.O. \& Pfefferbaum, A. (2000)Longitudinal changes recognition, gait, and balance in abstinent and relapsed alcoholic men: Relationships to changes in brain structure. Neuropsychology, 14, 178-188.

The Talking Pen: Wayne Engineering,1974

Victor, M., Adams, R. D., \& Collins, G. H. (1989). The Wernicke-Korsakoff Syndrome: And Related Neurologic Disorders Due to Alcoholism and Malnutrition (No. 30). FA Davis Company.

Welch, L.W., Cunningham, A.T., Eckardt, M.J. \& Martin, P.R. (1997). Fine Motor Speed Deficits in Alcoholic Korsakoff's Syndrome. Alcoholism: Clinical and Experimental Research, 21, 134-138.

York, J.L., Biederman I (1991) Hand movement speed and accuracy in detoxified alcoholics. Alcohol Clin Exp Res 15:982-990.

(This research is a dissertation work done while doing $M$. Phil in Medical \&Social Psychology, Session-2009-2011 at RINPAS) 